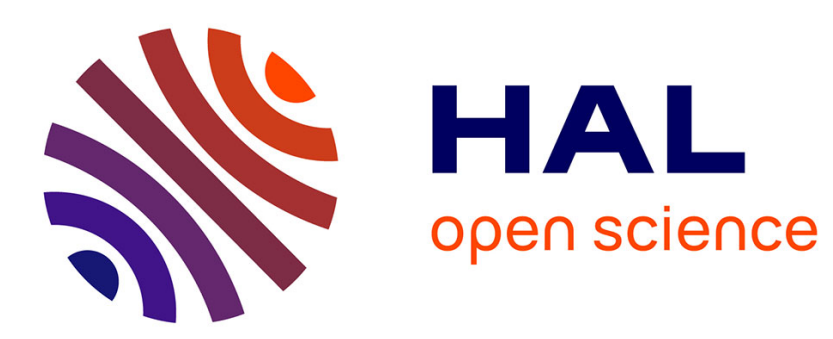

\title{
Online capacitor early ageing monitoring and detection using a dynamic reference model
}

Ramin Qaedi, Ebrahim Farjah, Teymoor Ghanbari, Yvan Avenas

\section{To cite this version:}

Ramin Qaedi, Ebrahim Farjah, Teymoor Ghanbari, Yvan Avenas. Online capacitor early ageing monitoring and detection using a dynamic reference model. Iet Science Measurement \& Technology, 2020, 14 (9), pp.731-738. 10.1049/iet-smt.2019.0556 . hal-03260232

\section{HAL Id: hal-03260232 \\ https://hal.science/hal-03260232}

Submitted on 14 Oct 2021

HAL is a multi-disciplinary open access archive for the deposit and dissemination of scientific research documents, whether they are published or not. The documents may come from teaching and research institutions in France or abroad, or from public or private research centers.
L'archive ouverte pluridisciplinaire HAL, est destinée au dépôt et à la diffusion de documents scientifiques de niveau recherche, publiés ou non, émanant des établissements d'enseignement et de recherche français ou étrangers, des laboratoires publics ou privés. 


\title{
Online capacitor early aging monitoring and detection using a dynamic reference model
}

\author{
Ramin Qaedi ${ }^{1}$, Ebrahim Farjah ${ }^{1 *}$, Teymoor Ghanbari ${ }^{2}$, Yvan Avenas ${ }^{3}$ \\ ${ }^{1}$ School of Electrical and Computer Engineering, Shiraz University, Namazi Square, Shiraz, Iran \\ ${ }^{2}$ School of Advanced Technologies, Shiraz University, Eram Square, Shiraz, Iran \\ ${ }^{3}$ Univ. Grenoble Alpes, CNRS, Grenoble INP, G2Elab, 38000 Grenoble, France \\ *farjah@shirazu.ac.ir
}

\begin{abstract}
This paper deals with a new approach for real time detection of early aging in dc-link electrolyte capacitors of DC-DC converters. The method is based on comparison between slope of the inductor current derived from a reference dynamic model and that of measurement. All of the normal deviations of the system parameters including gradual aging of the capacitor and impact of the operating temperature are taken into account in the reference model. Since parameters of the reference model are set in accordance with datasheets of the components, the reference slope represents normal gradual aging of the capacitor. Therefore, any early aging emerges in the measured slope. An accelerated aging test bench was implemented to assess the proposed method, by which early aging is emulated by experiments. The results confirm the performance of the method for the early aging detection.
\end{abstract}

\section{Nomenclature}

\begin{tabular}{|c|c|}
\hline$A E C$ & Aluminium electrolytic capacitor \\
\hline ESR & Equivalent series resistance \\
\hline LCR meter & $\begin{array}{l}\text { A device for measuring inductance, } \\
\text { capacitance, and resistance }\end{array}$ \\
\hline$R C$ & Rogowski coil \\
\hline$i_{L}$ & Inductor current \\
\hline$S I$ & Subinterval \\
\hline$R N S$ & Reference numerical slope \\
\hline$M N S$ & Measured numerical slope \\
\hline$C C$ & Consecutive cycle \\
\hline$S$ & Switching signal \\
\hline
\end{tabular}

\section{Introduction}

Nowadays, power electronic converters have become widely used in many engineering systems. Since failure of these converters leads to failure of the whole system, their security and reliability are in high degree of importance [1]. One of the main reasons of failure in power electronic converters is early aging of their components. Useful lifespan of power electronic components, determined by the manufactures may be less than the guarantied lifespan in practice due to different harsh operating conditions such as high temperature cycling, power cycling, and other environmental conditions. If the trend of aging for a component is normal, it is expected that the component has the guarantied lifespan. In this condition, some parameters of the components deviate during the lifespan which is normal from the user perspective. But in case of any early aging condition, the variations are abnormal and should be detected to be considered in the system monitoring and maintenance. This detection helps to rectify the resolvable origins of the early aging and replacement of the component in periodic maintenance to improve reliability of the system. Therefore, aging monitoring is a vital measure to achieve the required reliability and robustness of the systems [2].

The main components of power electronic converters with high rate of failure are DC link capacitors, PCB, power semiconductor modules, and solder joints as shown in Fig.1 [3]. Among them, DC link capacitors are more vulnerable to early aging and about $30 \%$ of failures in power converters are related to these components, which may be originated by an early aging [4]. This is why early aging of DC link capacitors has been more investigated compared with the other components in literature [5].

Since DC link capacitors are generally AEC type, therefore, in this work early aging of this type of capacitor has been investigated in details. Low cost, high density of energy, considerable value of capacitance, and voltage rating are the main merits of AEC in practice [6].

Several mechanisms have been reported for describing early aging phenomenon in AECs [7]. In general, degradation of the dielectric and the oxide layers performance due to thermal and electrical stresses is the main cause of early aging [8]. In practice, early aging is experienced as an increase in the ESR of the capacitor as well as a decrease in its capacitance [9].

In AECs, evaporation of the electrolyte and degradation of the oxide layer, caused by electrical and mechanical stresses during prolonged periodic normal operation or harsh conditions are the main reasons for the early aging [10]. Variation of the mentioned parameters in

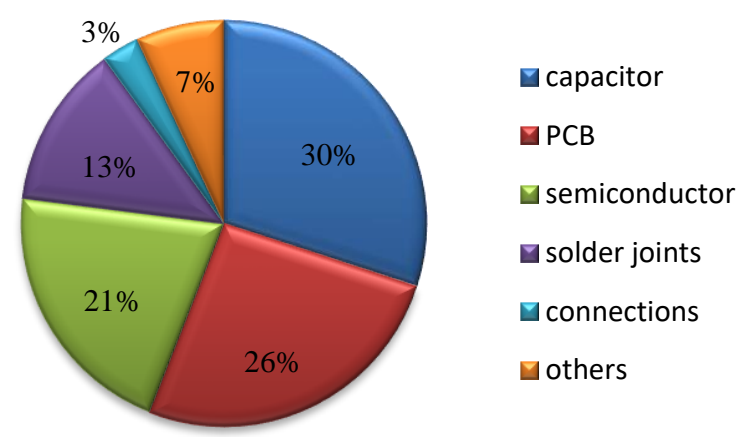

Fig. 1. Portion of major failure causes in power electronic converters [3] 
early aging condition may be used as signatures for detection of this situation in DC link capacitors.

Aging monitoring of the AECs have been investigated in some researches, which can be classified into two categories: online and offline approaches. Generally, offline techniques are simple and more accurate, but the capacitor should be fully disconnected from the relevant circuitry for the assessment. One of the conventional offline aging monitoring techniques is based on measurement of ESR using a high-precision LCR meter [11]. Although, online aging monitoring techniques are more complex, they are attractive and preferred for real time monitoring of the converters. Various techniques have been proposed in literature for online aging monitoring of the DC link capacitors. A comprehensive review on the aging monitoring approaches of the capacitors in power electronic converters has been presented in [12]. Various methods have been compared from different aspects and research gaps have been addressed in this regard. In [13], an online technique for aging monitoring of AECs has been suggested, which is based on monitoring of ESR and capacitance using voltage and current ripples of the capacitor. Also, online monitoring of ESR in DC-DC converters using output voltage of a fixed $\mathrm{RC}$ on the capacitor terminals has been proposed in [14]. In [15], another online ESR estimation method has been suggested, which is based on analyzing output voltage and inductor current of the converter. An independent index from operating temperature of the system has been presented in [16] for capacitor aging prognosis in automotive drive applications. This index is defined as the ratio between measured ESR and the expected ESR for a new capacitor. In [17], a non-invasive technique has been proposed for calculation of ESR and capacitance of the DClink capacitor in power factor correction boost converter. It was shown that since both ESR and capacitance contributes in the output voltage ripple, they could be calculated using only two values of the capacitor voltage in particular moments within a life cycle. In [18], a method has been proposed for aging monitoring of the DC-link capacitor in industrial power converters. This method is based on online estimation of the ESR using the switching frequency components of the DC-link capacitor voltage and capacitor current. An online technique for calculation of ESR and capacitance of the capacitor in the buck converters has been presented in [19]. The calculation was carried out based on AC component of the capacitor voltage in continuous conduction mode.

Although the reviewed proposed methods for online aging monitoring of AECs have some merits, more researches should be carried out on this topic for maturity of the techniques. Among the methods, the RC-based technique is more attractive because monitoring of the current deviation is an inherent capability of the sensor. However, in this method ESR was computed using a simple relation between the parameters without considering dynamics of the converter. In fact, reference value of the ESR was considered a fixed value in [14], while it varies because of normal aging during the capacitor lifespan. In this paper, early aging of AECs in DC-DC converters is detected using a dynamic reference model, in which all of the normal deviations of the system's parameters like normal aging of the capacitor and impact of temperature on the inductor and semiconductor resistances are considered. To do this, a dynamic model of the converter is used for deriving a time-varying reference parameter. Also, using a RC-based technique actual values of this parameter are measured in real-time to compare with the correspondence reference values for detection of the early aging. Parameters of the reference model are set considering data sheets and pristine condition of the components as well as normal gradually variation of the AEC's parameters. The reference parameter is calculated from two states, derived by solving the state-space reference model. In the early aging condition, a difference is experienced between the measured parameter and the calculated reference values.

In order to emulate early aging condition in the laboratory, an accelerated aging test bench was implemented. Plenty of experiments were carried out and the results are captured to assess the proposed method in practice.

A comparison with more detail will be presented between the performance of the proposed method and some other similar approaches. Thanks to utilization of the dynamic reference model and just one low-cost sensor, the proposed early aging approach could be a good alternative in this regard. In a short comparison, the proposed method has some merits compared with the other methods like simplicity, accuracy, cost-efficiency, and applicability for different DC-DC converters.

In the rest, Section 2 is assigned to presentation of the proposed online capacitor aging monitoring algorithm in more detail. The performance of the proposed algorithm is evaluated using some experiments for a typical DC-DC boost converter in Sections 3. Finally the main results are concluded in Section 4.

\section{The proposed online capacitor aging monitoring algorithm}

In this paper, slope of the inductor current $\left(i_{L}\right)$ is utilized to monitor the early aging of electrolytic capacitors in DC-DC converters. Here, the aging monitoring algorithm is explained for a DC-DC boost converter as an example. Fig. 2 shows the circuit of a DC/DC boost converter considering non-ideal components.

When switch $\mathrm{S}$ is in on-state, the inductor is charged in loop\#1. The inductor current in this subinterval $\left(\mathrm{SI}_{1}\right)$ is:

$$
\begin{aligned}
& i_{L}\left(S I_{1}\right)= \\
& \frac{V_{i n}}{R_{L}+R_{D S-O N}}\left(1-e^{-\frac{\left(R_{L}+R_{D S-O N}\right)}{L} t}\right)+I_{0} e^{-\frac{\left(R_{L}+R_{D S-O N}\right)}{L} t}
\end{aligned}
$$

where, $R_{L}$ and $R_{D S-O N}$ are parasitic resistance of the inductor and switch, respectively. Also, $I_{0}$ is the initial value of the inductor current.

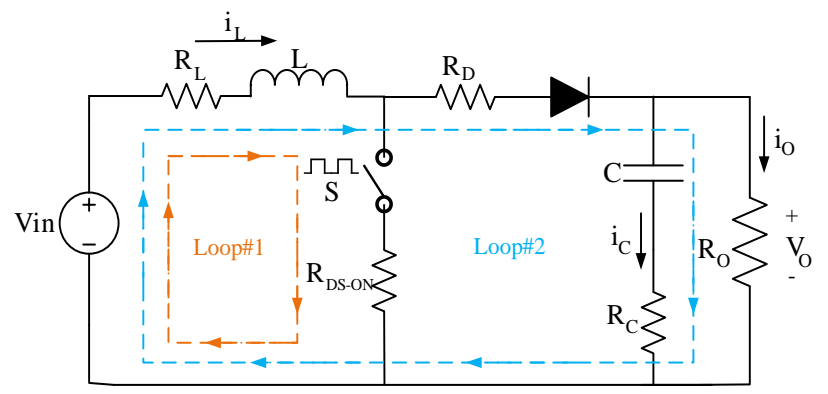

Fig. 2. DC-DC boost converter with non-ideal components 
When $\mathrm{S}$ is in off-state, the inductor is discharged through loop\#2. Following second order differential equation is written for the inductor current in this subinterval:

$$
\frac{d^{2} i_{L}}{d t^{2}}+\left(\frac{R_{L}+R_{D}+E S R}{L}\right) \frac{d i_{L}}{d t}+\frac{1}{L C} i_{L}=\frac{V_{O}}{L C R_{O}}
$$

where, $R_{D}$ is parasitic resistance of the diode and $V_{O}$ is supposed as a constant value. In this equation, damping coefficient is $\alpha=\frac{R_{L}+R_{D}+E S R}{2 L}$ and resonant frequency is $\omega_{0}^{2}=\frac{1}{L C}$. It is evident that the damping coefficient is directly proportional to the $E S R, R_{D}$, and $R_{L}$. Given that being in under-damped condition, the inductor current in this subinterval (SI2) is:

$$
\begin{aligned}
& i_{L}\left(S I_{2}\right)=e^{-\alpha t}\left(A \cos \left(\omega_{d} t\right)+B \sin \left(\omega_{d} t\right)\right) \\
& \omega_{d}=\sqrt{\alpha^{2}-\omega_{0}^{2}}
\end{aligned}
$$

In Fig. 3.a, the inductor current variation for two values of ESR is shown. As observed, the inductor current in the first subinterval does not affect after changing the ESR, while damping coefficient of the inductor current in the second subinterval varies in this condition.

Since one of the early aging signatures is the increase in the ESR, variation of the damping coefficient could be used for early aging detection. But, a good criterion is needed to quantify the deviation of damping coefficient in case of early aging. Here, the slope of the inductor current in the second subinterval is used as the criterion. Slope of the inductor current is shown in Fig 3.b.

It should be noted that equivalent series resistances of the inductor and diode also affect the damping coefficient. Although rate of aging of these components is very not so high, variation of their resistances are significant due to temperature variations in different conditions. However, all

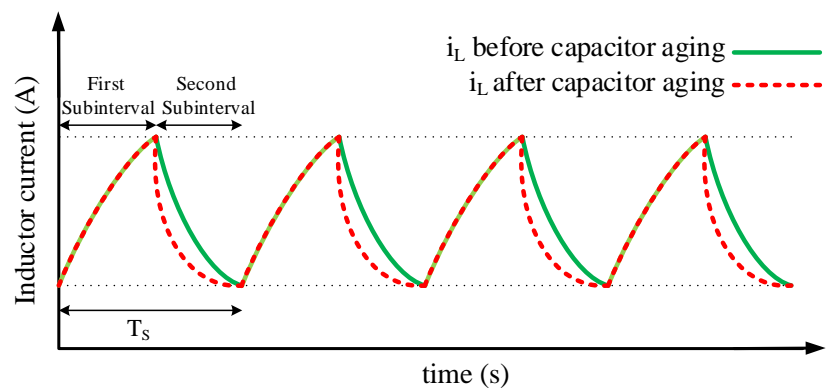

(a)

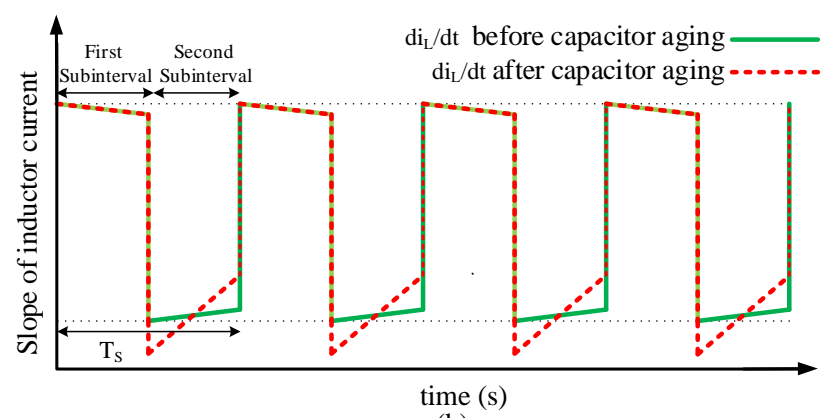

(b)

Fig. 3. Early aging impact on the inductor current waveform

a) The inductor current b) Slope of the inductor current of these normal variations can be taken into account in the reference model by considering thermal model of the converter components in this model. Therefore, the main origin of the damping coefficient variation refers to capacitor ESR variation, could be reached to about $300 \%$ in aging condition.

Therefore, the proposed method is based on a comparison between two slope signals as shown in Fig. 3 b. In the next subsections, the utilized techniques for driving these signals are explained in more detail.

The first slope signal of the inductor current, shown in green, is derived by a state space model of the converter as the reference slope signal. Parameters of the model are set considering datasheets of the components as initial setting and gradual increase in the ESR relevant to normal aging of the capacitor is also included in the reference model. In every cycle of the switching, two samples of the $d_{L} / d t$ signal $\left(\mathrm{di}_{\mathrm{L}, \mathrm{m}} / \mathrm{dt}\right.$ and $\left.\mathrm{di}_{\mathrm{L}, \mathrm{n}} / \mathrm{dt}\right)$ are recorded for the second subintervals. The RNS is calculated by $\left(\mathrm{di}_{\mathrm{L}, \mathrm{m}} / \mathrm{dt}-\right.$ $\left.\mathrm{di}_{\mathrm{L}, \mathrm{n}} / \mathrm{dt}\right) /\left(\mathrm{t}_{\mathrm{m}}-\mathrm{t}_{\mathrm{n}}\right)$ for each second subinterval. Since aging has a long time dynamic, such calculation could be performed in a periodic time intervals to reduce the computational burden. Duration of these time intervals can be chosen considering rate of early aging of the capacitors and specifications of the

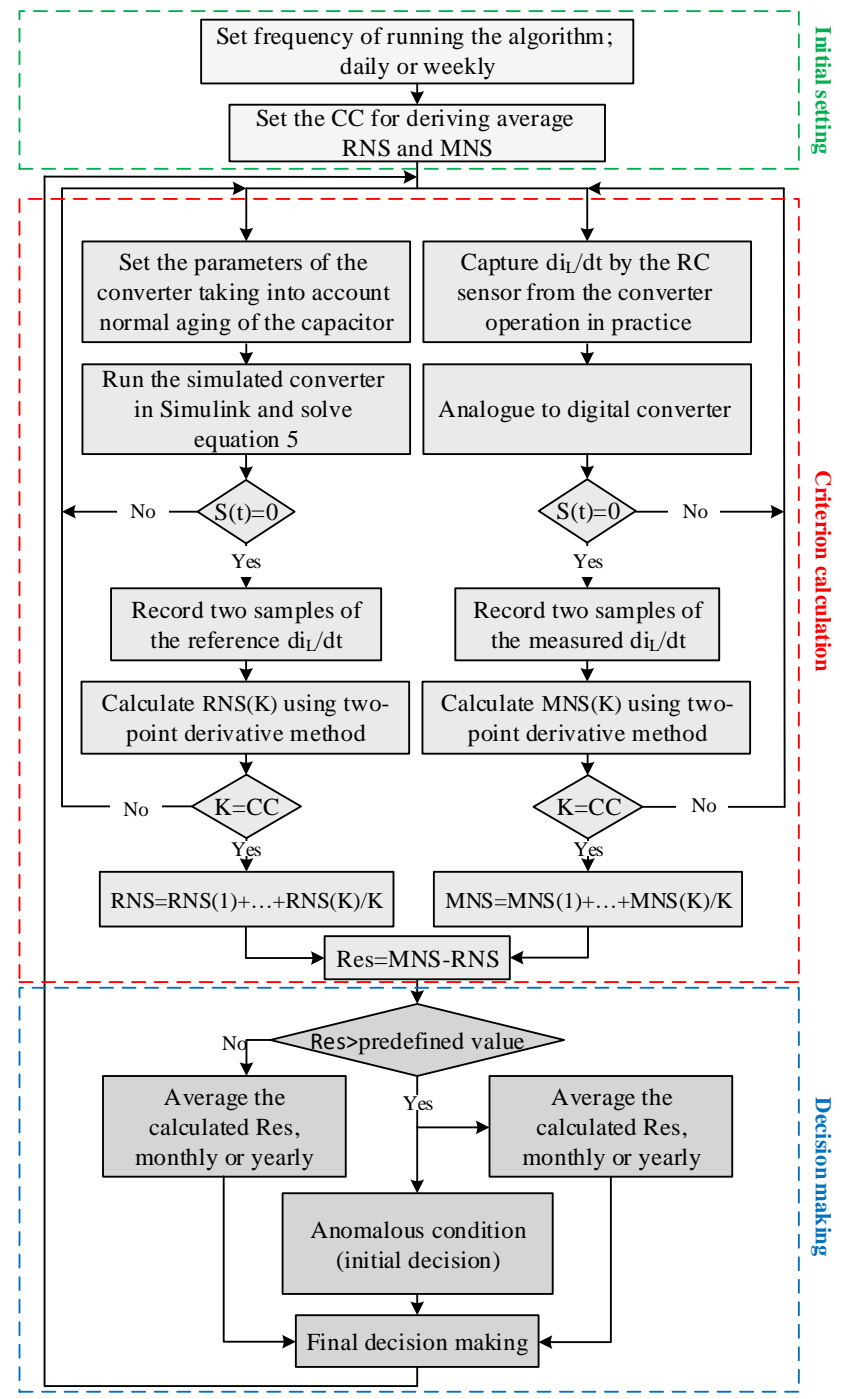

Fig. 4. Flowchart of the proposed early aging detection algorithm 
employed processor.

The second slope signal of the inductor current, shown in red, is measured by a fabricated prototype $\mathrm{RC}$ in practice. By the same process for deriving the RNS, the MNS is also calculated. Since the captured signal by the RC refers actual condition of the converter, the considered signature of the capacitor early aging can be acquired from this signal.

The reference slope signal is a digital signal, derived by solving the model continually; however, the captured signal by the RC is an analog signal, which should be passed through an A/D unit for calculation of the MNS. Moreover, the other derivation approaches can be utilized instead of the used two-point derivation method to obtain the numerical slops more efficiently.

In the final step, both the numerical slopes are compared and if the compared value is deviated from a predefined threshold, the early aging condition is reported. Flowchart of this algorithm is shown in Fig. 4.

In order to increase the robustness of the method against different noises, average of calculated RNS and MNS in several CC of the slope signals should be considered. In this paper two consecutive cycles are considered for calculation of average RNS and MNS. It is essential to compare the corresponding measured and simulation data for the detection. Therefore, both systems should be synchronized at the first step of running the algorithm. Since the reference model is aimed to be modeled in a processor, by which the converter is derived, such synchronization is straightforwardly.

In order to assess the proposed method, an experimental accelerated aging was carried out in this work. To do so, first the capacitor was imposed to a periodic electrical stress condition. Then this capacitor was installed in the converter and variation of the ESR is monitored when the converter is under operation.

\subsection{State space model of the system}

In order to derive the reference slope signal of the inductor current, the converter is simulated using state space model of the system. As mentioned, all of the system's parameters are set in accordance with datasheets of the components in the converter under study. Dynamic operation of the converter can be represented by the following state-space equations [20]:

$$
\begin{aligned}
& \dot{x}(t)=A x(t)+B u(t) \\
& y=C x(t)
\end{aligned}
$$

in which, $A, B$ and $C$ are the model coefficients. Also, $x(t)$ and $u(t)$ are the state variables and inputs of the system, respectively. By defining $x(t)=\left[i_{L}(t) v_{C}(t)\right]$ and $u(t)=\left[v_{\text {in }} v_{\text {out }}\right]$ for a boost converter considering normal aging of the capacitor, the equations can be rewritten as:

$$
\left[\begin{array}{c}
\frac{d i_{L}}{d t} \\
\frac{d V_{c}}{d t}
\end{array}\right]=A\left[\begin{array}{l}
i_{L}(t) \\
V_{c}(t)
\end{array}\right]+B\left[\begin{array}{l}
V_{i n} \\
V_{o}
\end{array}\right]
$$

$y=\left[\begin{array}{c}i_{L}(t) \\ V_{c}(t)\end{array}\right]=C\left[\begin{array}{c}i_{L}(t) \\ V_{c}(t)\end{array}\right]$

where,

$A=\left[\begin{array}{cc}-\frac{R_{L}}{L}-\frac{S R_{O N}}{L}-\frac{(1-\mathrm{S}) \cdot\left(E S R+R_{D}\right)}{L} & -\frac{(1-\mathrm{S})}{L} \\ \frac{(1-\mathrm{S})}{C} & 0\end{array}\right]$

$B=\left[\begin{array}{cc}\frac{1}{L} & \frac{(1-S) \cdot E S R}{L R_{o}} \\ 0 & -\frac{1}{C R_{o}}\end{array}\right]$

$C=\left[\begin{array}{ll}1 & 0 \\ 0 & 1\end{array}\right]$

In this model, $S$ is the switching signal. When the switch is on, $S=1$ and when the switch is off, $S=0$. By solving equation (7), di $\mathrm{i}_{\mathrm{L}} / \mathrm{dt}$ can be derived for calculation of the RNS.

\subsection{Real time measurement of the slope of inductor current}

The capacitor current is the same as inductor current ripple in the converter. For measurement of the capacitor current, a current sensor like Hall-effect sensor can be utilized. In [21], a printed circuit board type RC was used for measurement of the capacitor current. Instead of the capacitor current, one can measure variation of the inductor current using a sensor installed in series with the inductor. By elimination of the DC term, its ripple current can be derived. Also, using a flux-based current sensor, the inductor current ripple can be measured. Here, a suitable RC sensor is employed around the inductor to measure the ripple current. The utilized $\mathrm{RC}$ has a linear response for wide range of frequency, low cost, and simple implementation even for the already fabricated converters [2]. Schematic of the utilized RC sensor is shown in Fig. 5.

Derivative of the inductor current can be calculated by the Faraday law on the RC as follows:

$$
\frac{d i_{L}}{d t}=V_{R C S} / M
$$

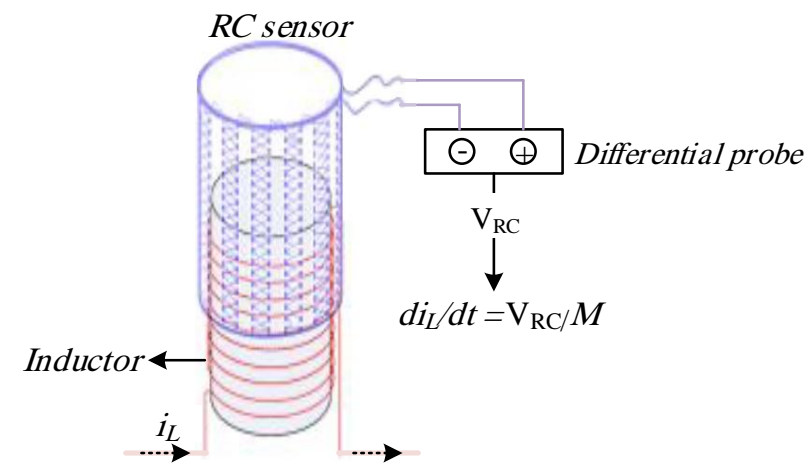

Fig. 5. Schematic of the utilized RC sensor 
where, $M$ and $\mathrm{V}_{\mathrm{RCS}}$ are mutual inductance and output voltage of the $\mathrm{RC}$, respectively. By measuring voltage across the inductor, mutual inductance of the $\mathrm{RC}$ can be derived as follows:

$$
M=\frac{L V_{R C S}}{V_{L}}
$$

After measurement of $\mathrm{di}_{\mathrm{L}} / \mathrm{dt}$, this signal is passed through the analogue to digital converter. Then, by dividing difference of every two consecutive samples on the sampling time, MNS is calculated in real time.

\subsection{Procedure of determining the threshold value}

In order to determine the predefined threshold, the following procedure should be followed:

A. Extracting the normal lifespan curve of the capacitor: First, in order to extract the normal lifespan curve, the useful lifespan and the increase in the ESR (ESR $\left.\mathrm{EOL}_{\text {L }}\right)$ in the end of life should be determined using the datasheet of the capacitor. Then, according to [22], the useful lifespan curve of the capacitor is obtained as an exponential curve as Fig. 6a. In this figure $\alpha$ and $\beta$ are model constants and can be obtained using $\mathrm{ESR}_{\mathrm{IN}}, \mathrm{ESR}_{\mathrm{EOL}}$, and $\mathrm{T}_{\mathrm{UL}}$.

B. Multi-line approximation of the exponential curve: In this step, the exponential curve is approximated into $\mathrm{N}$ lines and their slopes are determined. Accuracy of the threshold value can be enhanced by increasing number of the lines $(\mathrm{N})$.

C. Considering a specific percentage of life reduction as an early aging: In this step, a specific percentage of lifespan reduction is considered as the early aging condition considering the importance of its detection. For example, one could consider $40 \%$ reduction in the useful life of the capacitor as the early aging condition $\left(\mathrm{T}_{\mathrm{EA}}=60 \% \times \mathrm{T}_{\mathrm{UL}}\right)$.

D. Extracting the early aging lifespan curve: Then, the early aging lifespan curve of the capacitor is obtained as Fig. 6b. In this figure $\delta$ and $\gamma$ are model constants and can be obtained using $\mathrm{ESR}_{\mathrm{IN}}, \mathrm{ESR}_{\mathrm{EOL}}$, and $\mathrm{T}_{\mathrm{EA}}$.

\section{E. Multi-line approximation of the early aging curve:}
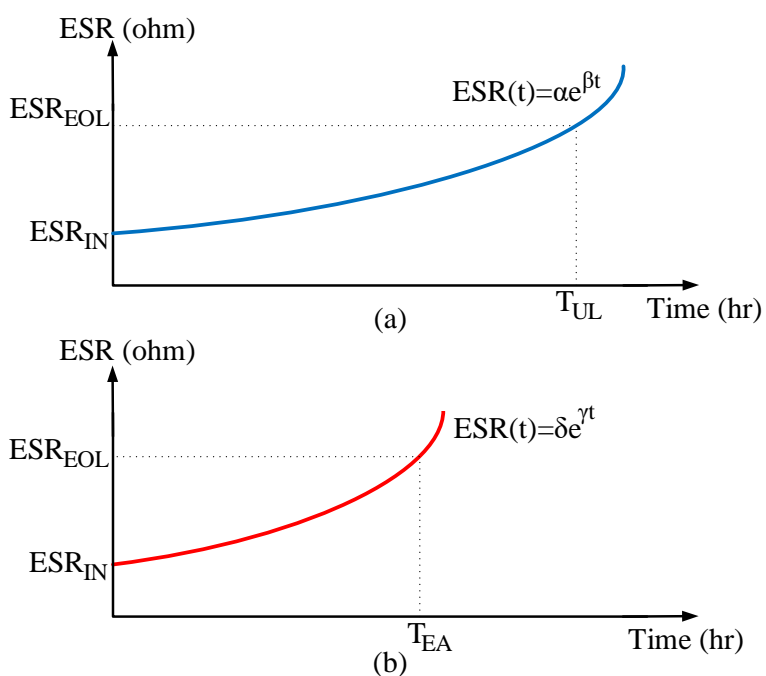

Fig. 6. Capacitor lifespan curves. (a) Normal lifespan curve (b) Early aging lifespan curve
In this step, early aging curve is also approximated into $\mathrm{N}$ lines and their slopes are determined.

F. Calculation of differences between the corresponding slopes: Differences between the corresponding slopes of the lines in both the curves are calculated. Then, percentages of increase in the corresponding slopes are determined.

G. Calculation of percentage increase in the ESR: By simulation, percentage of the ESRs increment corresponding to the calculated slopes' increment in the previews step is determined.

H. Calculation of percentage increase in the MNS: Then, percentage of the ESRs increment is applied to the separate simulations to find the corresponding increment of the MNS. The percentage of increase in the MNS is considered as the threshold.

It should be noted that one could divide the lifespan of the capacitor into some equal periods and for each of them average of the slopes' increments are considered in the abovementioned procedure. In this case, some different thresholds are determined for the time intervals. Also, average of all the slopes' increments in the lifespan can be used in the procedure, which results in one specific threshold value.

\subsection{Comparison between the proposed aging monitoring technique and other methods}

The proposed aging monitoring technique is compared with some of the similar aging monitoring techniques, reviewed in the introduction, from different aspects.

The early aging detection methods can be broadly categorized into online and offline approaches. Since the suggested method in this work is an online approach, just some similar online techniques are considered for the comparison.

The method proposed in [13]: This technique is based on online estimation of the ESR and capacitance of the capacitor. In this technique by measuring the input current and output voltage of the converter, the ESR and capacitance values have been determined using a Kalman filter. In this method additional electrical sensors are required for the detection. Also, different dynamics of the converter in different operation conditions have not taken into account. Moreover, computational burden of this method is relatively high.

The method proposed in [14]: This method is based on online calculation of ESR of the capacitor. The ESR has been calculated using the output voltage of a fixed RC on the capacitor terminals by a simple relation. This method is cost efficient because of using only one electrical sensor for the aging monitoring. The main drawback of this method is that all the dynamics of the converter are not considered, which affect accuracy of the method, negatively.

The method proposed in [15]: In this approach an online ESR estimation technique has been suggested to monitor the aging of output capacitors in DC-DC boost converters. The ESR was calculated by measuring the output 
voltage and the inductor current of the converter. In order to reduce the ESR estimation error, wavelet transform denoising was used to eliminate the high-frequency noises in the sampled signals which increase the accuracy of technique. The main drawback of this method is the need of additional sensors.

The method proposed in [17]: This technique is based on online monitoring of the ESR and capacitance of the capacitor. In this method calculation of the ESR and capacitance was performed by measuring only two values of the capacitor voltage in some particular moments. This aging monitoring technique uses just one electrical sensor, but some additional monitoring circuitry are needed for measuring two values of the capacitor voltage, which increases the cost and complexity.

The method proposed in [18]: This method is an online aging monitoring technique, based on estimation of the ESR of the capacitor. The method estimates the ESR using switching frequency components of the dc-link capacitor voltage and current. The ESR value was estimated by extracting peak values of the capacitor voltage and current as well as phase difference between these two signals. The main disadvantage of this method is the need of two electrical sensors for aging monitoring which increases the cost.

The method proposed [19]: A non-invasive online identification method has been suggested in this reference, by which ESR and capacitance of the capacitor are calculated for a buck converter in continuous conduction mode. Considering ac component of the capacitor voltage, a model for calculation of ESR and capacitance was derived. Using the PWM signal and output voltage of the converter, the method does not need to any current sensor. The main disadvantage of this method is using additional monitoring circuitry to extract ac components of the capacitor voltage which increases the cost and complexity.

As mentioned, the main disadvantages of the reviewed methods for online aging monitoring are: using additional sensors, using additional monitoring circuitry, and not considering different dynamics of the converter in different operation conditions. In the proposed early aging technique just one low cost sensor is employed and no additional monitoring circuitry is needed for the monitoring. Also, in the proposed method all different the dynamics like gradual normal aging of the capacitor and impacts of operating temperature are taken into account in the reference model which increases the accuracy of the method.

Main key points of the comparison are tabulated in Table 1. As observed in the table it can be concluded that the proposed method is relatively a good alternative for early aging detection between the methods from different aspects.

\section{Experimental validation}

In order to demonstrate the effectiveness of the proposed online aging monitoring algorithm, some experiments have been carried out. The experiments are performed in two different steps. In the first step, by using an accelerated aging test bench, a periodic overvoltage stress is applied to a set of electrolytic capacitors in order to
Table 1 Comparison between electrolytic capacitors aging monitoring methods

\begin{tabular}{|c|c|c|c|c|c|}
\hline Reference & $\begin{array}{c}\text { Aging } \\
\text { indicator }\end{array}$ & Application & complexity & Accuracy & Cost \\
\hline [13] & $\mathrm{ESR} / \mathrm{C}$ & $\begin{array}{l}\text { Uninterrupted } \\
\text { power } \\
\text { supplies } \\
\text { (UPS) }\end{array}$ & Complex & Low & High \\
\hline [14] & ESR & $\begin{array}{c}\text { DC-DC } \\
\text { converters }\end{array}$ & Simple & Low & Low \\
\hline [15] & ESR & $\begin{array}{c}\text { Boost } \\
\text { converter }\end{array}$ & Moderate & High & High \\
\hline [17] & $\mathrm{ESR} / \mathrm{C}$ & $\begin{array}{c}\text { Boost PFC } \\
\text { converter }\end{array}$ & Moderate & Medium & Medium \\
\hline [18] & ESR & $\begin{array}{l}\text { Industrial } \\
\text { power } \\
\text { converters }\end{array}$ & Moderate & Medium & High \\
\hline [19] & $\mathrm{ESR} / \mathrm{C}$ & $\begin{array}{c}\text { Buck } \\
\text { converter }\end{array}$ & Moderate & Medium & Medium \\
\hline $\begin{array}{c}\text { Proposed } \\
\text { method }\end{array}$ & ESR & $\begin{array}{c}\text { DC-DC } \\
\text { converters }\end{array}$ & Simple & High & Low \\
\hline
\end{tabular}

emulate early aging condition. In the second step, after using the capacitors in a boost converter, rate of aging of them is determined by the proposed method. These steps are described in more detail in the following subsections. Fig. 7 shows the utilized test bench to evaluate the proposed algorithm.

\subsection{Accelerate aging of the capacitor}

Several factors cause aging of the electrolytic capacitors. Prolonged operation under normal condition and operation under stress condition such as electrical stress and thermal stress are two important factors of aging in these devices. Since the aging process of an electrolytic capacitor is very time-consuming under normal conditions, the process of aging monitoring becomes difficult; therefore, systematic degradation of the capacitor should be simulated under high stress conditions in shorter period of time. Some studied have been presented in the literature to monitor the aging of AECs under stress conditions. In [8] the aging of electrolytic capacitors used in the DC-DC converters has been investigated under electrical overstress operation conditions. The aging of these capacitors was monitored over the total 180 hours of accelerated aging time through measuring aging data for ESR every 8-10 hours. SP-150 Biologic SAS electro-impedance spectroscopy is used periodically during the test to capture the aging data for ESR. The aging process of electrolytic capacitors under thermal overstress was also investigated in [23]. Electrical and thermal stresses are the main causes of early aging. In this paper, a periodic electrical stress is applied to the capacitors

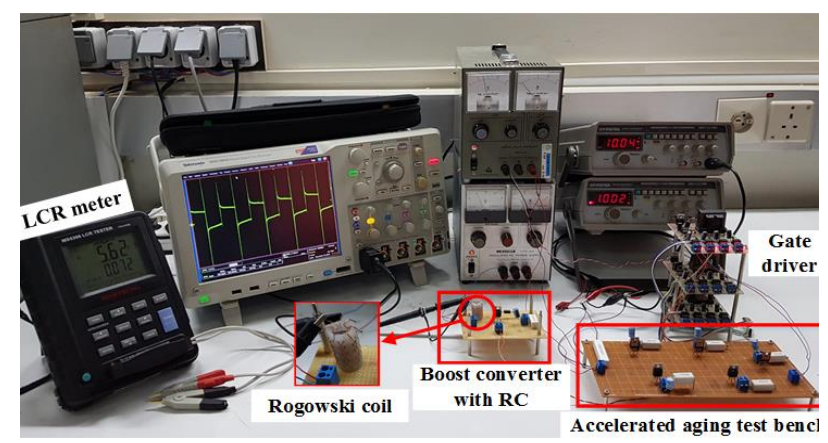

Fig. 7. The utilized test bench to evaluate the proposed aging monitoring algorithm 


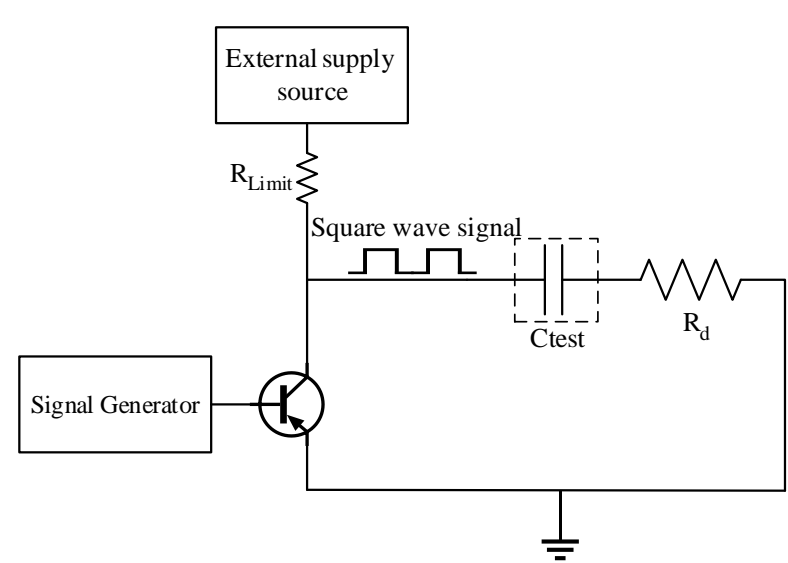

Fig. 8. Schematic diagram of the accelerated electrical overstress test bench

for implementation of accelerate aging. Here, the proposed method in [8] is utilized in which a periodic high-voltage stress is imposed to several capacitors. After applying the stress for a specified duration, they are checked by measuring their ESR to select the capacitors which have reasonable variation of the parameters regarding the accelerated aging. This is why several capacitors instead of one capacitor are subjected to high-voltage stress. Fig. 8 shows schematic diagram of the accelerated electrical overstress test bench.

The applied overvoltage to the capacitors is a square waveform with amplitude of $15 \mathrm{~V}$ and fixed frequency of 1 Hz. Five electrolytic $470 \mu \mathrm{F}$ capacitors, with a maximum rated voltage of $10 \mathrm{~V}$, and maximum operating temperature of $105{ }^{\circ} \mathrm{C}$ are considered for the experiments. In order to complete discharge of the capacitors before the next charging cycle, resistors with $R_{d}=100 \Omega$ are connected in series with the capacitors. Also, in order to limit shortcircuit current passing through the switches when it is in ON state, $R_{\text {Limit }}=20 \Omega$ is connected in series with the source. A picture of the utilized test bench for the accelerated aging is shown in Fig. 7.

Since the proposed method is based on detection of ESR variation, here values of ESR for the tested capacitors are monitored in the experiments. The experiment of accelerated aging was performed during about 160 hours, which includes 20 periodic tests with 8 hours duration. Fig. 9 shows the measured values of ESRs for each capacitor throughout the tests. As expected, by increasing the duration of applied electrical overstress to the capacitors, values of ESRs increase over the time. In the first test, the capacitors were subjected to the overvoltage stress for 8 hours. Then, their ESRs were measured to be compared with the initial ESR values using a MASTECH MS5308 LCR TESTER.

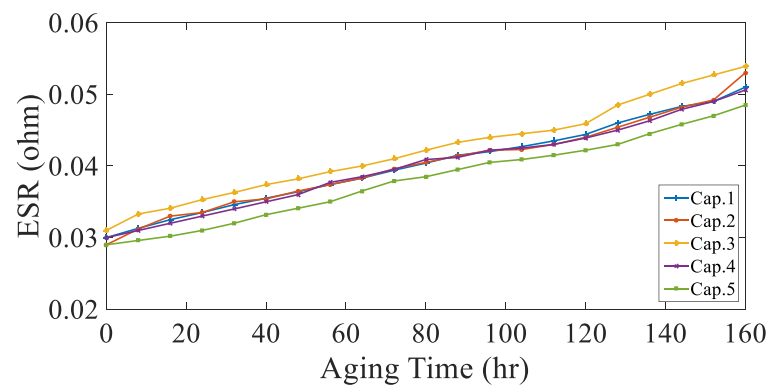

Fig. 9. The measured value of ESRs during the accelerated aging tests
After that one of the capacitors, which experienced reasonable change in the ESR, is selected for the other periodic tests. This capacitor was used in the converter for evaluation of the proposed method. During each measurement, the supply was turned off and the capacitors were discharged completely. It should be noted that the ambient temperature during the experiments was kept at the room temperature $\left(25^{\circ} \mathrm{C}\right)$ in order to exclude the ambient temperature effect on the aging.

\subsection{Assessment of performance of the proposed method}

As mentioned, in order to evaluate the performance of the proposed online aging monitoring algorithm, the selected accelerated aged capacitor is installed in the DCDC boost converter after each test. Then, variation of the ESR is monitored when the converter is under operation. Variation of the ESR is captured from the implemented and simulated converters. It should be mentioned that all parameters and specifications of the boost converter are the same except trend of ESR variation. In fact, in the simulated converter normal trend of ESR regarding the capacitor normal aging process is taking into account, while in the implemented converter ESR variation may be relevant to normal aging or early aging conditions. In order to model gradual variation of the ESR in normal aging, useful lifespan of the capacitor can be determined at $25^{\circ} \mathrm{C}$. Since the experiments for gathering the slope signals from the converter were carried out during short time intervals, the capacitor temperature is considered close to ambient temperature. In the capacitor datasheet, the useful lifespan was given 2000 hours at $85^{\circ} \mathrm{C}$, in which the ESR will be twice as much as the initial value after 2000 hours. Therefore, useful lifespan of the capacitor at $25{ }^{\circ} \mathrm{C}$ is determined by the following simple model [22]:

$\frac{L_{2}}{L_{1}}=2^{\frac{T_{1}-T_{2}}{10}} \Rightarrow L_{2}=2000 \times 2^{\frac{85-25}{10}}=128000 \mathrm{hr}$

In accordance with (12), the ESR will be twice as much as the initial value after 128000 hours at $25^{\circ} \mathrm{C}$. Therefore variation of the ESR in normal aging can be derived as follows [22]:

$\operatorname{ESR}(t)=\alpha e^{\beta t}$

where $\alpha$ and $\beta$ are model constants and can be obtained using the initial and final values of the ESR. Gradual variation of the ESR in normal aging procedure is shown in Fig.10. Furthermore, other normal variations of the system's parameters are considered in the reference model. For instance, impacts of operating temperature on the resistance of the inductor and diode are included in the model by the following relations [24]:

$$
\begin{aligned}
& R_{L}(T)=R_{L, \text { ref }} \times\left(1+\alpha\left(T-T_{\text {ref }}\right)\right) \\
& R_{d}(T)=R_{d, \text { ref }} \times \beta\left(T-T_{\text {ref }}\right)
\end{aligned}
$$

where $\alpha$ is thermal coefficient and $\beta$ is derived from the diode datasheet. 


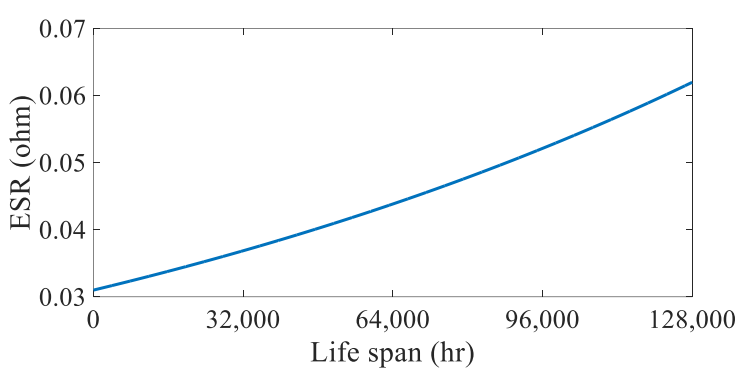

Fig. 10. Normal aging model of the capacitor

Table 2 The converter specifications

\begin{tabular}{cc}
\hline parameter & value \\
\hline $\mathrm{V}_{\text {in }}$ & $5 \mathrm{~V}$ \\
$\mathrm{R}_{\mathrm{L}}$ & $0.26 \Omega$ \\
$\mathrm{L}$ & $100 \mu \mathrm{H}$ \\
Duty cycle & 0.5 \\
$\mathrm{R}_{\mathrm{DS}-\mathrm{ON}}$ & $0.55 \Omega$ \\
$\mathrm{R}_{\mathrm{D}}$ & $0.5 \Omega$ \\
$\mathrm{C}$ & $470 \mu \mathrm{F}, 10 \mathrm{~V}$ \\
$\mathrm{R}_{\mathrm{O}}$ & $10 \Omega$ \\
Switching frequency & $10 \mathrm{KHz}$
\end{tabular}

The main specifications and parameters value of the simulated converter in MATLAB/SIMULINK are tabulated in Table 2. These specifications are set considering datasheets of the converter's components.

In order to compare numerical slopes, the reference model and actual converter should be run, simultaneously. To this end, one can run the reference model in the processor, by which the actual converter is derived. This strategy should be considered in the real field for the proposed method.

However, since the accelerated aging procedure for the capacitor was considered in the experiments, the reference model was simulated in MATLAB/SIMULINK. As mentioned, in the accelerated aging, the capacitor is imposed to overvoltage stress for 20 periodic tests with 8 hours duration. Therefore, the reference model is run for 160 hours and two cycles of the reference slope signal at the end of each 8 hours are recorded for the comparison. In Fig. 11a, the captured reference slope signals for the 20 periodic tests are shown.

In order to obtain the measured inductor current slope signal, the mutual inductance of the RC should be determined. To do so, the inductor voltage and the RC output voltage should be measured in normal condition. These signals are measured by a digital oscilloscope (Tektronix MSO5054) as shown in Fig. 12.

As shown in Fig. 12, peak to peak value of the inductor voltage is about $9 \mathrm{~V}$ and peak to peak value of the $\mathrm{RC}$ output voltage is about $240 \mathrm{mV}$. Using (11), the mutual inductance of the $\mathrm{RC}$ is derived as follows:

$M=\frac{L V_{R C S}}{V_{L}}=2.66 \mu H$

Now by measuring the $\mathrm{RC}$ output voltage and dividing on the mutual inductance, the measured inductor current slope signal can be obtained.

For the 20 periodic tests of the accelerated aging procedure, two cycles of the measured slope signal are recorded for each 8-hour cyclic test. These slope signals are shown in Fig.11b.

Now, numerical slope for each cycle of the reference and measured signals is calculated using two-point derivation method and are averaged over two cycles. Then, difference between the calculated numerical values for each

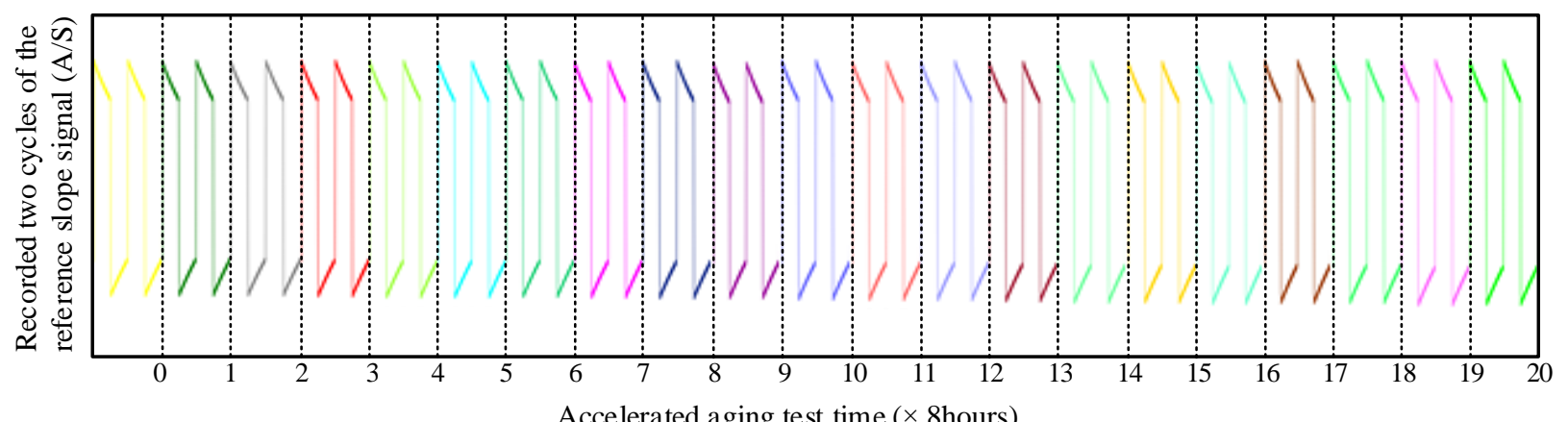

(a)

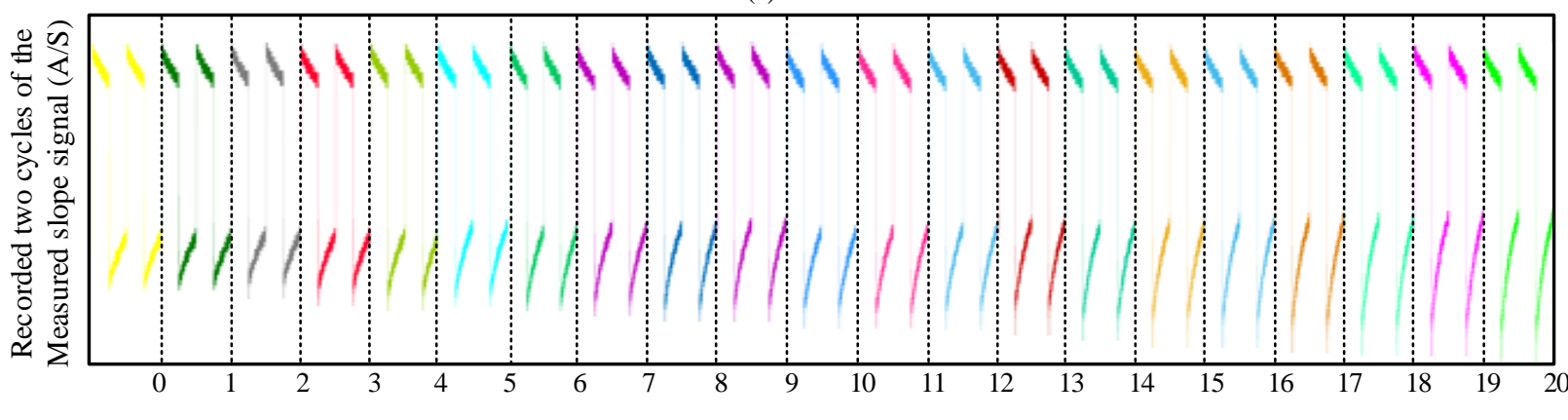

Accelerated aging test time $(\times$ 8hours $)$

(b)

Fig. 11. (a) The reference inductor current slope in normal condition, (b) The measured inductor current slope in the accelerated aging test 


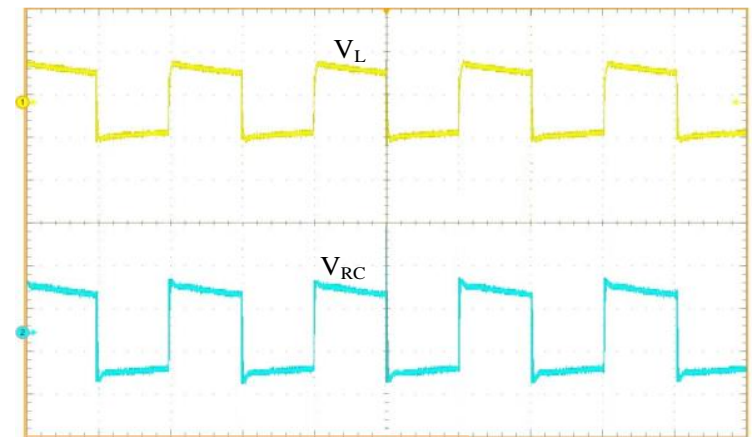

C1: 1 v/div

C2: $20 \mathrm{mv} / \mathrm{div}$ Horizontal: $10 \mu \mathrm{s} / \mathrm{div}$

Fig. 12. The signals of the boost converter in normal condition: c1: inductor voltage, c2: RC output voltage

two cycles is derived and considered as the early aging criterion. For the reference and measured signals shown in Fig. 11, the calculated average numerical values and percentage of increase in the MNS relative to RNS are shown in Fig. 13. It should be noted that the shown result in Fig.13a is just relevant to 160 hours of the useful life i.e. 128000 hours.

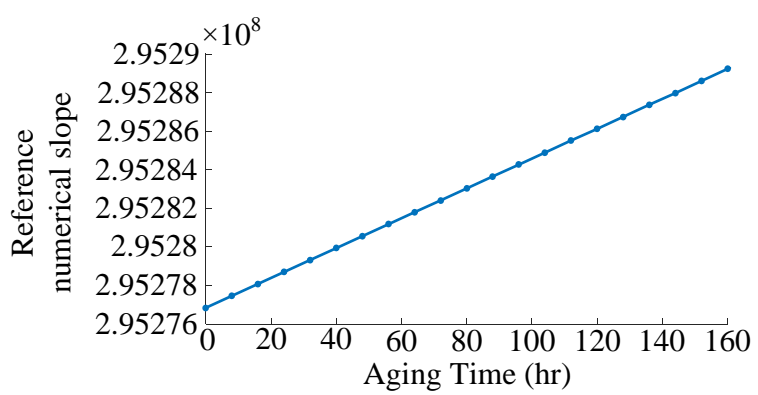

(a)

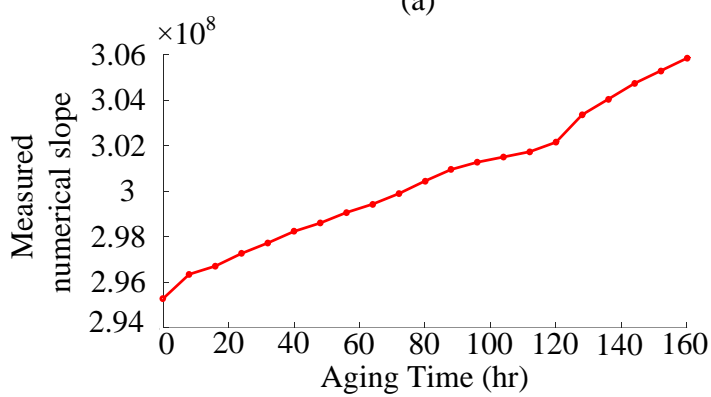

(b)

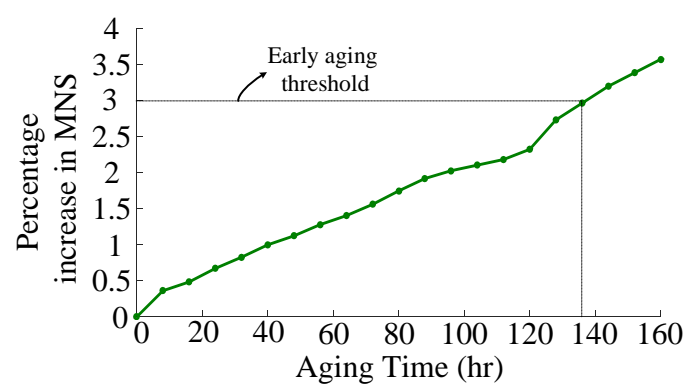

(c)

Fig. 13. (a) Numerical values of the reference slope signals, (b) Numerical values of the measured slope signals, (c) Percentage increase in measured numerical slope
Here, if $3 \%$ increase in the MNS appears, it is considered as an early aging condition. This threshold was chosen using the procedure of determining the predefined threshold which was discussed in the previous sections. As shown in Fig. 13, early aging is detected after 136 hours by this threshold.

\section{Conclusion}

An online aging monitoring technique was proposed for early aging detection of electrolyte capacitors in DC-DC converters. Slope of the inductor current as a criterion for the detection is measured using a fabricate prototype Rogowski coil and compared with the corresponding values derived from a reference dynamic model. In the reference model, normal variations of the system's parameters like gradual normal aging of the capacitor and impacts of operating temperature are taken into account. In order to evaluate the performance of the proposed technique, some experiments were carried out on an accelerated aging test bench. It was confirmed that the proposed method is able to detect any early aging condition at the early stages of the procedure. The method is simple and cost efficient, while its accuracy and speed are high enough to be used as an online aging monitoring.

\section{Reference}

[1] Chen, Y., Pei, X., Nie, S., Kang, Y., 'Monitoring and diagnosis for the DC-DC converter using the magnetic near field waveform', IEEE Transactions on Industrial Electronics, 2010, 58, (5), PP.1634-47.

[2] Givi, H., Farjah, E., Ghanbari, T., 'A Comprehensive Monitoring System for Online Fault Diagnosis and Aging Detection of Non-Isolated DC-DC Converters' Components', IEEE Transactions on Power Electronics, 2018, 34, (7), PP.6858-75.

[3] Wolfgang, E. 'Examples for failures in power electronics systems', ECPE tutorial on reliability of power electronic systems, Nuremberg, Germany, 2007, PP.19-20.

[4] Yang, S., Bryant, A., Mawby, P., Xiang, D., Ran, L., Tavner, P., 'An industry-based survey of reliability in power electronic converters', IEEE transactions on Industry Applications, 2011, 47, (3), PP.1441-51.

[5] Buiatti, G. M., Martin-Ramos, J. A., Garcia, C. H. R., Amaral, A. M., Cardoso, A. J. M, 'An online and noninvasive technique for the condition monitoring of capacitors in boost converters', IEEE Transactions on Instrumentation and Measurement, 2009, 59, (8), PP. 213443.

[6] Pu, X.S., Nguyen, T.H., Lee, D.C., Lee, K.B., Kim, J.M., 'Fault diagnosis of DC-link capacitors in three-phase AC/DC PWM converters by online estimation of equivalent series resistance', IEEE Transactions on Industrial Electronics, 2012, 60, (9), pp.4118-27.

[7] Brettle, J., Jackson, N., 'Failure mechanisms in solid electrolytic capacitors', Active and Passive Electronic Components, 1977, 3, (4), pp.233-46.

[8] Celaya, J., Kulkarni, C., Biswas, G., Saha, S., Goebel, K., 'A model-based prognostics methodology for electrolytic capacitors based on electrical overstress accelerated aging', 2011.

[9] Wang, H., Blaabjerg, F., 'Reliability of capacitors for DC-link applications in power electronic converters-An 
overview', IEEE Transactions on Industry Applications, 2014, 50, (5), pp.3569-78.

[10] Agarwal, N., Ahmad, M.W., Anand, S., 'Quasi-online technique for health monitoring of capacitor in single-phase solar inverter', IEEE Transactions on Power Electronics, 2017, 33, (6), pp.5283-91.

[11] Amaral, A.M.R., Cardoso, A.M., 'A simple offline technique for evaluating the condition of aluminumelectrolytic-capacitors', IEEE Transactions on Industrial Electronics, 2009, 56, (8), pp.3230-7.

[12] Soliman, H., Wang, H., Blaabjerg, F., 'A review of the condition monitoring of capacitors in power electronic converters', IEEE Transactions on Industry Applications, 2016, 52, (6), pp.4976-89.

[13] Abdennadher, K., Venet, P., Rojat, G., Rétif, J.M., Rosset, C., 'A real-time predictive-maintenance system of aluminum electrolytic capacitors used in uninterrupted power supplies', IEEE Transactions on Industry Applications, 2010, 46, (4), pp.1644-52.

[14] Givi, H., Farjah, E., Ghanbari, T., 'Switch fault diagnosis and capacitor lifetime monitoring technique for DC-DC converters using a single sensor', IET Science, Measurement \& Technology, 2016, 10, (5), pp.513-27.

[15] Ren, L., Gong, C., Zhao, Y., 'An Online ESR Estimation Method for Output Capacitor of Boost Converter', IEEE Transactions on Power Electronics, 2019.

[16] Rigamonti, M., Baraldi, P., Zio, E., Astigarraga, D., Galarza, A., 'Particle filter-based prognostics for an electrolytic capacitor working in variable operating conditions', IEEE Transactions on Power Electronics, 2015, 31, (2), pp.1567-75.

[17] Yao, K., Tang, W., Bi, X., Lyu, J., 'An online monitoring scheme of DC-link capacitor's ESR and $\mathrm{C}$ for a boost PFC converter', IEEE Transactions on Power Electronics, 2015, 31, (8), pp.5944-51.

[18] Sundararajan, P., Sathik, M.H.M., Sasongko, F., Tan, C.S., Tariq, M., Simanjorang, R., 'Online Condition Monitoring System for DC-Link Capacitor in Industrial Power Converters', IEEETransactions on Industry Applications, 2018, 54, (5), pp.4775-85.

[19] Yao, K., Tang, W., Hu, W., Lyu, J., 'A currentsensorless online ESR and C identification method for output capacitor of buck converter', IEEE Transactions on Power Electronics, 2014, 30, (12), pp.6993-7005.

[20] Alimeling, J., Hammer, W.P., 'PLECS-piece-wise linear electrical circuit simulation for Simulink', in, Proceedings of the IEEE 1999 International Conference on Power Electronics and Drive Systems, PEDS'99 (Cat No 99TH8475), 1999, pp.355-360.

[21] Venet, P., Perisse, F., El-Husseini, M., Rojat, G., 'Realization of a smart electrolytic capacitor circuit' IEEE Industry Applications Magazine, 2002, 8, (1), pp.16-20.

[22] Gasperi, M.L., 'Life prediction model for aluminum electrolytic capacitors', in, IAS'96 Conference Record of the 1996 IEEE Industry Applications Conference Thirty-First IAS Annual Meeting, 1996, pp.1347-1351.

[23] Kulkarni, C.S., Celaya, J.R., Goebel, K., Biswas, G., 'Physics based electrolytic capacitor degradation models for prognostic studies under thermal overstress', 2012.

[24] Shahjalal, M., 'Electric-thermal modelling of power electronics components', Doctoral dissertation, University of Greenwich, 2018. 